\title{
Total Challenge: A Serious Game for Stimulating Cognitive Abilities
}

\author{
http://dx.doi.org/10.3991/ijac.v9i1.4903 \\ Vítor H. Carvalho, Tiago Martins, Filomena Soares, Miguel Araújo \\ University of Minho, Braga, Portugal
}

\begin{abstract}
If properly used, the high potential of students' digital literacy may be used to help them benefit from education. Education efficiency may lie in applying the concept of "fun" learning that characterizes the so-called "serious games" that promote competitiveness. This type of game can also be used to solve or mitigate problems involving health care, more specifically those relating to intellectual disabilities and autism spectrum disorders, within which there is still much study to be performed. In this sense, we present the Total Challenge, a game oriented to learning which stimulates cognitive abilities of children, but whose potential can be also used to monitor the progress of people with intellectual disabilities or autism spectrum disorders.
\end{abstract}

Index Terms-Autism spectrum disorders, competitiveness, education efficiency, "fun" learning, intellectual disabilities, serious game.

\section{INTRODUCTION}

For too long, game playing was considered by some authors as a futile activity, centered only on entertainment. However it was recognized as extremely important in human cognitive development by other authors [1].

Among the latter, we can refer the Dutch teacher, historian and philosopher Johan Huizinga. In his book Homo Ludens (1938), he recognizes the game as an activity essential to life as the reasoning and the objects manufacturing but different from daily life [2]. Huizinga's view seems to have been a premonition of what is currently happening with video games, in which a virtual existence is created as an extension of real life [3].

Games that have emerged to accomplish a main objective, beyond mere entertainment (including knowledge transmission to the player) are called serious games. The high potential of this approach has been used, among others, for military purposes, training of top athletes, rehabilitation and education at several levels. Such games involve challenges and use reward systems in order to motivate the users to continue until the purpose is reached [4-8].

Serious games can make a contribution to solve problems in different areas such as education, because in a world where the latest technological wonder becomes obsolete in a short time and the student has experienced other forms of observing reality, traditional classes tend to be unpleasant and not very motivating [9].

Students are accustomed to using social networks, such as Facebook, which allows the creation of specific groups for members, guaranteeing a closed communication platform for the course users, accessible at any time or place, with specific privileges for each user. They are also famil- iar with collaborative online tools, for example Google Drive or Microsoft One Drive, that allow the simultaneous content edition, by several users, especially useful for personal productivity in text documents, data sheets, among others or simply the file-sharing storage tools as Dropbox.

So, in his/her dual task of motivating and teaching, a teacher can benefit from this huge potential of students' digital literacy to introduce, in the classroom, technological innovations that create a ludic component that enriches and encourages young people to teaching and learning activities. One way to carry this entertainment component to the learning environment can be reached with the use of serious games in the classroom context. Students can experiment with their ideas, converting them into a lived experience, making their learning more solid and effective [9].

Therefore, the potential of these technological resources in the education area allows responding suitably to the high standards of competitiveness.

Taking into account the characteristics of the serious games, it is possible with their use, to transform the way how students learn. And, differently from what happened with other technologies used in education, right from the beginning of their development, the potential of these games as an educational tool did not only center in mainstream education but also was extended to the specific case of people with intellectual disabilities or, in particular, with autism spectrum disorder, presenting them with new ways to acquire knowledge and strengthening skills that allow them to reduce the impact of their disabilities [10].

Intellectual disability and autism spectrum disorder are related to the degree to which the intellectual and adaptive functioning of a person are below the average level that occurs in the general population [11]. These problems should be considered and analyzed as a set of limitations that determine the way how the individual adapts to the social environment and to his/her life conditions, with his/her limitations and capabilities [12].

So, finding stimuli through fun repetition and a gradual increase in the level of challenge, allows students with these types of disabilities to become less dependent, taking charge of their own learning [10].

Serious games have a marked importance in the case of people with intellectual disabilities or autism spectrum disorder. In fact, although they tend to behave passively, with this interactive software such students may actively involve themselves in their learning and work at their own rhythm [10]. 
The enormous potential that serious games offer, namely the possibility of being adapted to the individual needs and also to reproduce any situation, under the same conditions and as often as one likes, convert these technologies in a support of excellence for people with disabilities [13].

Holders of these deficiencies have cognitive functional limitations in terms of perception, motor skills, memory, attention, self-regulation, language, social development, motivation and effective mobilization of cognitive abilities [12].

These individuals show an impaired cognitive functioning, since the acquisition of knowledge requires a personal effort of structuring and creating new relationships. Some studies have led to conclusions that allow to state that it is essential to provide them with an intellectual support to help them to structure intelligent behaviors, which appear spontaneously in normal development. However, it is not expected that with this support people with these types of disability are able to achieve the impossible, this is, that their cognitive frames will experience a full reversal. Whatever the support, it is never a curative treatment of these deficiencies, as they are irreversible, but a complement to the traditional tools [14].

Cognition which relates to the capabilities that allow people to think, to perceive things, to reach, to understand and to respond to information, permitting them to function in their daily life, is significantly affected in the case of individuals with intellectual disabilities. Attention, memory, problem-solving and organization of information ability are some of these capabilities [15].

Concerning the autism spectrum disorders, the exclusive, aggressive, or excessively emotional behaviors can gradually be reduced with the use of serious games. These can provide the means to increase and enrich their social relations. They find groups, observe habits and build interpretations, becoming themselves the source of new relations. Furthermore they develop their capacity to feel, act, reflect and imagine, while they spread their experiences, explore the world and rise their knowledge [16].

It is known that the use of games allow people with intellectual disabilities to learn according to their rhythm and their capabilities, and provides integration with the world, through relationships and experiences [17].

Taking into account what has been referred above, the goal of this paper is to present a tool developed by our research team to set available to children attending the first four years of school. This tool can also be used to monitor the progress of patients with intellectual disabilities or autism spectrum disorder, with regard to memory, decision-making time, observation capacity, learning and application knowledge.

This paper is structured as follows: Section II presents some examples of serious games as educational and therapeutic tools; Section III shows the developed serious game "Total Challenge"; Section IV enunciates some final remarks about the project.

\section{Serious Games as Educational AND Therapeutic TOOLS}

The students are prevented to experience certain situations in the real world by factors such as safety, cost, time, among others, which hinders their understanding [18]. We can find one solution to this problem using serious games as a learning tool. An example can be a security factor.
There will be a high probability of an accident if an army uses real weapons to train their strategies. Nevertheless, as serious games are realistic and immersive, the training of different military tactics through these games is as productive as in real life, with the advantage that accidents cannot occur [19].

In the following we present some examples of serious games, given the advantages arising from their use in learning contexts.

\section{The Oregon Trail (Fig}

. 1) developed in 1971 and based on real events was one of the highly successful games. Its original purpose was to teach school children the realities of life of the pioneers of the nineteenth century settlers, in Oregon Trail, a historical route between the Missouri River and the valleys of Oregon, in the western United States of America [20].

In 1983 the game Math Blaster! was developed, recreating a rescue story in a futuristic universe, which requires the player to learn mathematical skills [21].

Also for math skills learning, the game Number Munchers (Fig. 2) was designed in 1986. It consists of a grid square, with a numerical expression or word. This grid is roamed by deadly monsters that the player must avoid while controlling a green character (Muncher). The goal is to consume all the squares that meet a certain criteria (multiples, factors, primes, equality, inequality), stipulated by the game mode [22].

For players to use the electromagnetism physics to load their spaceship (a charged particle) and navigate through the three-dimensional space to achieve a goal was developed The Supercharged! game (Fig. 3). The player needs to know the relationship between load and distance. To facilitate navigation towards the ultimate goal the players have to put loads within the three-dimensional environment [23].

A game that provides several challenges to drag the periodic table of chemical compounds to a test tube is MyQuímica. The user can get information about the selected elements as well as the compound that constitutes the challenge. This game shows the ranking at the end of each round and allows to go to the next challenge, even if the player is not successful in several attempts, thus promoting students motivation [24].

In ActivChemistry game a chemistry lab (Fig. 4) is available that is a kit that provides equipment and materials to students, such as Bunsen burners, chemicals, and a

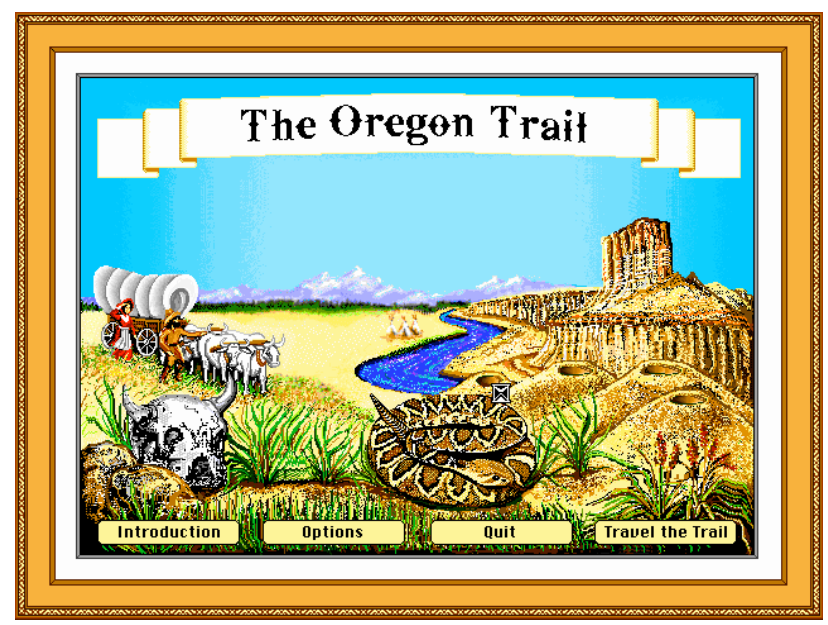

Figure 1. Screenshot of "The Oregon Trail"[20] 


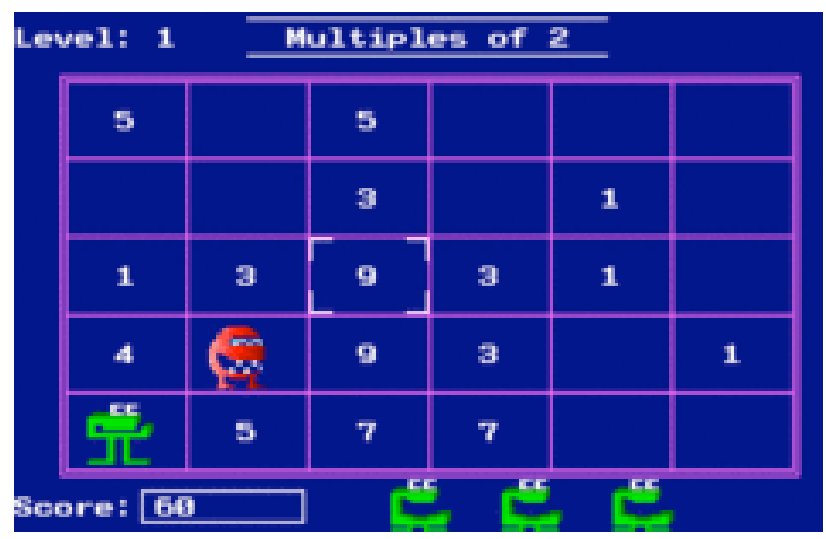

Figure 2. Screenshot of the "Number Munchers" [22]

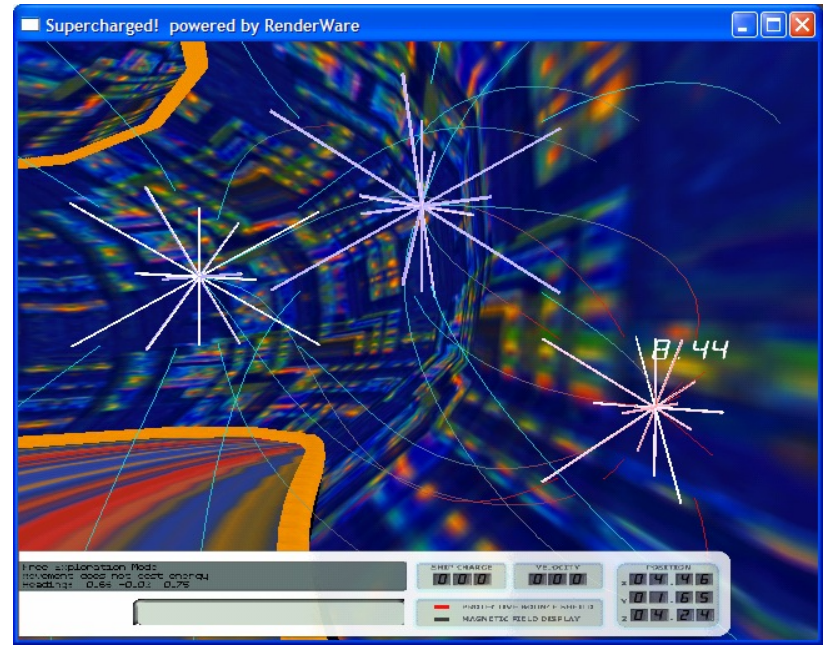

Figure 3. Screenshot of "Supercharged!" [23]

wide variety of gauges and indicators. With these materials they can conduct experiments, collect data and represent them graphically, and learn new concepts, in interactive and dynamic lessons. Compared to actual equipment, ActivChemistry presents several advantages. Security that the game provides allowing to perform experiences without problems and avoiding dangerous situations is one of the advantages. The cost savings avoiding the acquisition of expensive equipment and materials is another advantage. Finally, there is the learning efficiency: students using the game do not feel the pressure of time, usually in the chemistry lab, and often complete tasks at a faster rhythm [25].

The serious game Where in the world is Carmen Sandiego? (Fig. 5) is a classic in which the player plays the role of a detective who must catch the most cunning of thieves called Carmen Sandiego. In order to identify a place near where Carmen is, the game is leaving clues that the player must decipher. In general, the clues are true facts about actual geographical locations. So, the player learns the geographic locations deciphering these clues. It is, therefore, a game that focuses on world geography, flags, and coins [26].

In order to decrease the difficulty to learn to program, a serious game called Castle of Puzzles was created (Fig. 6). This game is based on the story of a student who only starts to study at night, for a programming test in the next day. But he falls asleep and dreams that he is in a castle. However, he does not lose the awareness that he needs to

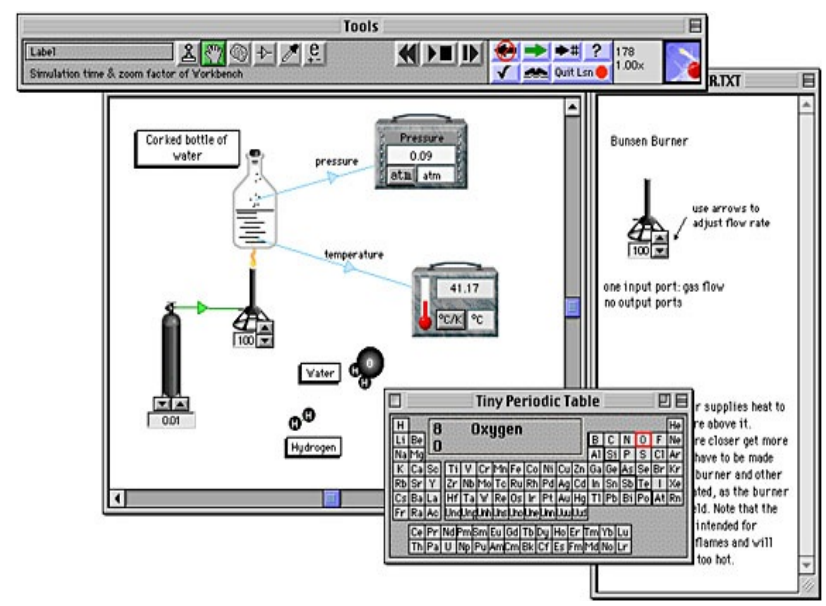

Figure 4. Screenshot of "ActivChemistry" [25]

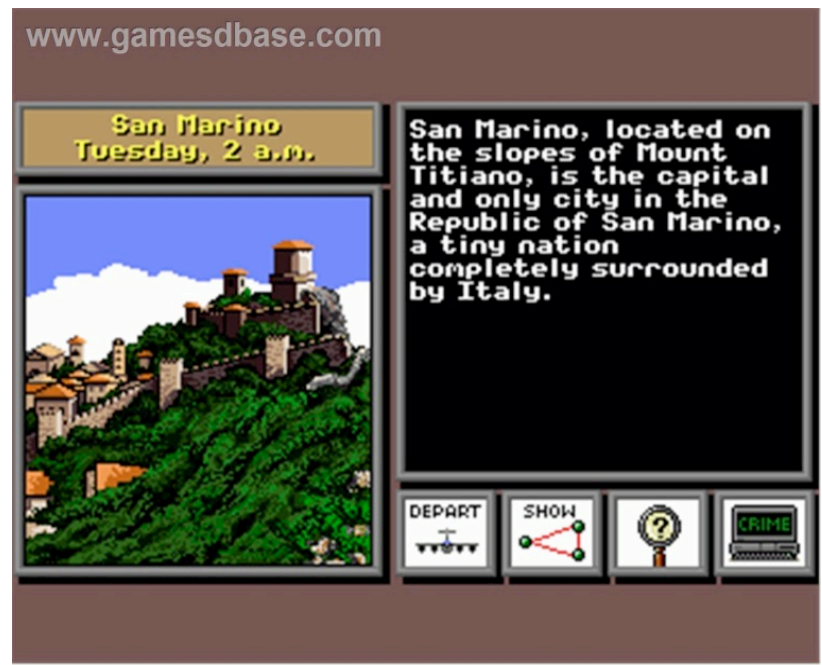

Figure 5. Screenshot of "Where in the world is Carmen Sandiego?" [26]

get out to go to the exam. The player is confronted with several challenges, which can be obstacles that he/she can only overcome if he/she uses logical reasoning to solve a problem or instances of exploitation, where he/she has to defend and to attack. As the different conquered challenges correspond to studied subjects the player realizes he/she is learning. In the castle there are several rooms where are objects that the player can use, which is equivalent to activate certain useful actions for the puzzle solution [27].

To help students with intellectual disabilities in their activities of daily life, Lanyi and Brown [13] designed and developed ten serious games. In order to maximize their accessibility and their use, these researchers considered to be of extreme importance to minimize skills and capabilities necessary for the user to navigate within the game. So they used charts for navigation, animations and sound signal, according to the published design guidelines in order to encourage user involvement and provide alternatives to the text.

Knowing that there are individuals with autism spectrum disorder that interact well with the new technologies and can benefit from their use, some researchers created a system composed of a set of serious games targeted for first aid education: what to do in certain situations, basic knowledge about health, medical specialties, among others. [28]. 
Also, in order to improve collaboration skills in children with an autism spectrum disorder, other scientists developed a serious game with multi-touch interaction [29].

\section{The Design of the Serious GAme}

According to several studies the use of new technologies in education awakens the students' attention to matters that otherwise seemed boring. Thus, the authors developed the serious game Total Challenge, a dynamic work environment that allows students to become more involved in different activities and to understand and consolidate knowledge.

The target group of this application consists of children attending the first four years of school or people with mild or low moderate intellectual disabilities or spectrum autism disorder.

\section{A. General Outline of the Game}

Since our goal is to track and improve the development of these people in terms of decision making, perception, association, memory and other cognitive abilities, it was necessary to build a system to monitor these developments and then send the data for analysis.

The historical record is only possible if each user/tutor, at home or at school, ensures that the system is connected to a central database via Internet. In fact the game can be played in online and offline modes (Fig. 7). In online mode, the connection to the Internet is required but it offers the advantage to give the player a new level of competitiveness and consequently a superior motivation (he/she can fight for a top spot in the online ranking) also allowing the investigator to check the progress of the users. For the user to register in the official game site with his/her personal data (name, date of birth, responsible tutor) the help of a tutor may be necessary. In order to play, each user must enter the identification (user ID) assigned after completing the registration as well as the password.

The result of each player is sent to a central server which stores all the data, at the end of each game, (Fig. 8). This centralization has two functions: it allows the investigator to access to all data for research purposes; the other allows the user or his/her tutor to access the results, and therefore to analyze the evolution over time, through the game's official website. The difficulty level is directly related to the response time, the complexity of the contents and the number of rounds for each game level. In order to optimize all these parameters the researchers can change them at any time. When people are training or when the device where the game is running does not have Internet access, offline mode is the most suitable. It also allows to set all parameters of the game, such as response time, the number of rounds each level, among others. However, in this mode and since he/she has the possibility to know the parameter values, the player does not compete with others for rankings, except with him/herself.

\section{B. User Interface}

The interface is simple as it was especially designed for children and people with intellectual disabilities or spectrum autism disorder (Fig. 9). It is worth mention that the game interfaces were written in Portuguese.

The entire game is controlled with only three buttons (blue, yellow and red). These buttons can be attached to

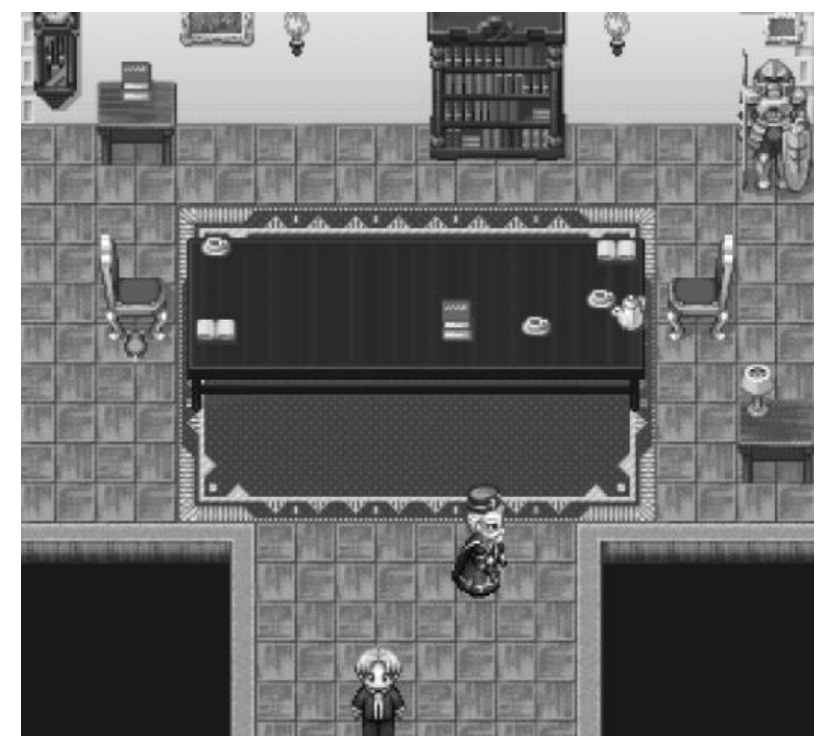

Figure 6. Screenshot of "Room of the Castle" [27]

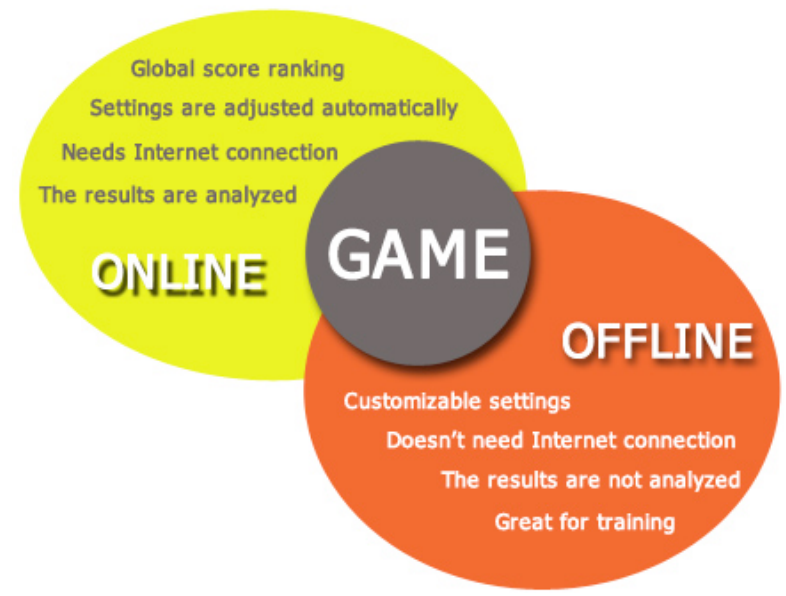

Figure 7. Game modes

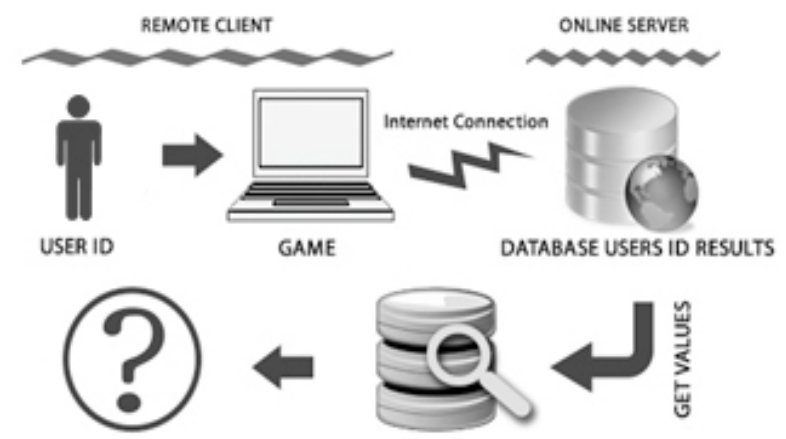

FINAL RESULTS \& CONCWUSIONS USERS ID RESULTS ANALYSE

LOCAL SERVER

Figure 8. General outline of the application

keys or a specific command that allow carrying out actions properly identified on the screen, such as fast forward, rewind and select (Fig. 10).

To facilitate the understanding of all areas of the game in the Total Challenge voice aids were implemented, though they are also written in text form. These voices have friendly and fun shades, also transmitting sometimes motivational messages such as "Congratulations", "For the next time try to be more careful", among others. 


\section{Idea and Design}

The game is divided into four main sections, with a short introduction in the early part (Fig. 11). The first section, Instructions, presents a little help for the correct use of the game. In the second section, Ranking, are presented the results of the top 10 played, by difficulty level. The section "Settings", allows the user to login for the online mode and parameterize the offline mode, as well as voice support. The section "Play" refers to the game itself, which is divided into three challenges.

The three proposed challenges are based on interactions with images of different categories (transport, animals, and clothing) and test memory, decision-making time, ability of observation, association, player perception and other cognitive disorders (Fig. 12).

In the first challenge, are presented randomly, three images, two of them belonging to a different category of the remaining. The player's goal is to find the intruder, that is, the image that is outside the context of the others. In this challenge are mainly tested the ability of perception, decision-making, association and categorization.

The second challenge tests particularly the ability of observation and memorization of the player through three images of different categories, randomly generated. After a period of observation the images are shuffled and the player has a certain amount of time to reorganize them according to the initial order.

In the third challenge, three images of different categories (without repetition) are randomly generated and presented by means of sound and text. The player must select the image that corresponds to this category. With this challenge we test especially the categorization capacity and knowledge application of the player.

The categories range from the general to the specific knowledge depending on the difficulty level, testing the capabilities of the players relating to the decision-making, since there are different response times for the different degrees of difficulty.

The higher the degree of difficulty is, the higher will be the complexity of the presented categories. For example, in the easy level it will only be shown general categories such as clothing, animals, and transports; but, if the difficult level is selected, more specific categories will be presented, such as air, land, sea transports, among others.

The difficulty level can be directly related to the required education level. Thus we consider that the player must attend at least the 1st grade to play on the easy level, 2 nd or 3 rd grade in medium level and 4 th grade in the difficult level.

Within the scope of intellectual disability or autism spectrum disorder, the difficulty level is directly related to the degree of disability.

For each challenge a maximum response time is associated to each difficulty level. This time can be parameterized in game settings, if we are playing in offline mode; however, in online mode, these settings are automatically adjusted.

For each correct answer there is a fixed score of five points that is multiplied by the remaining time by the timer, that is, the quicker is the answer the higher is the score.

After each challenge, the player can only advance to the next if he/she has a minimum score equivalent to $2 / 3$ of

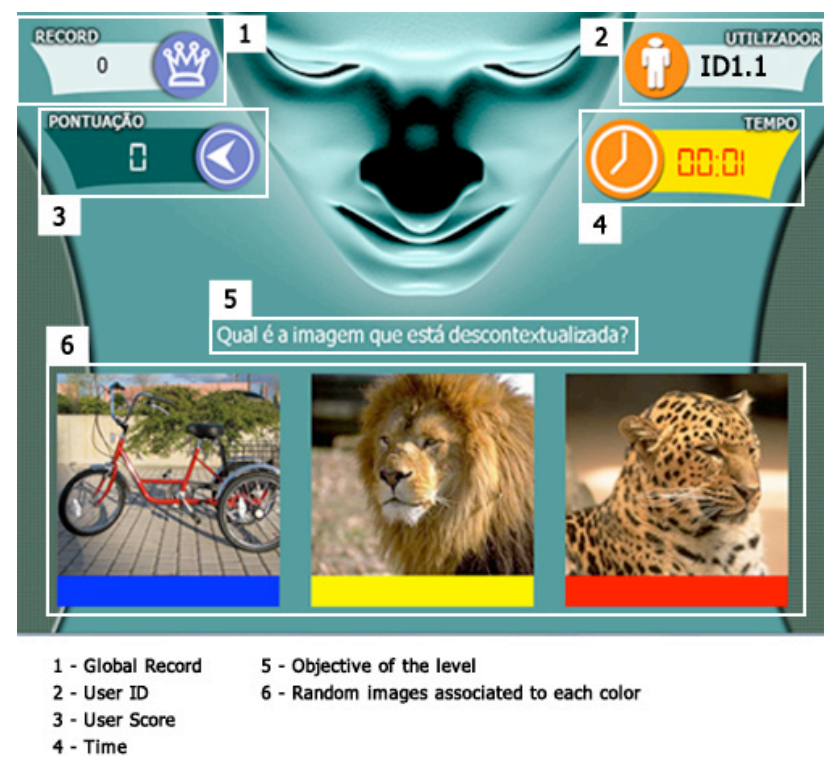

Figure 9. Game Interface

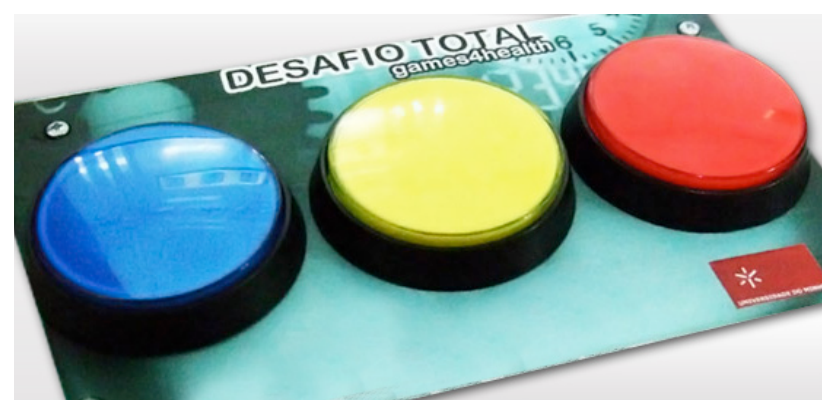

Figure 10. Controller pad

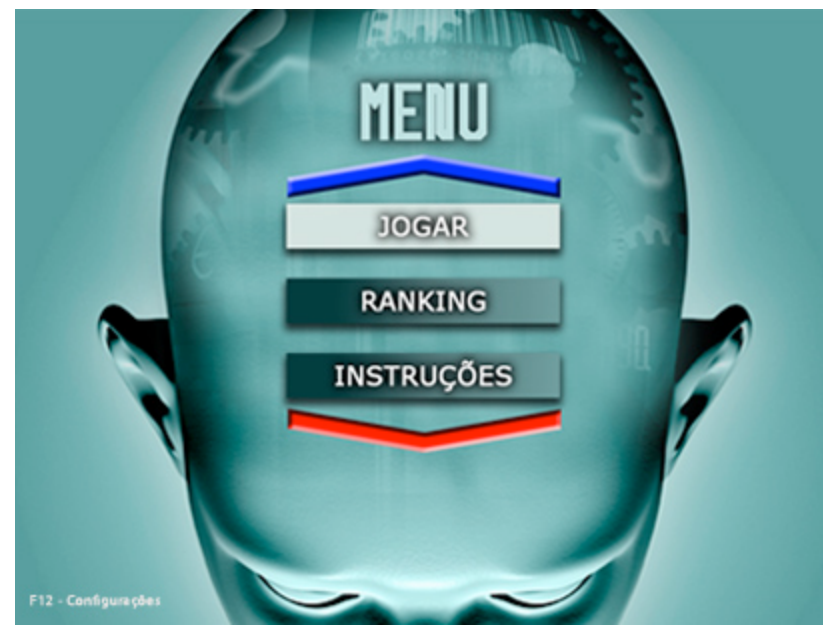

Figure 11. Main menu

the total challenge score in the worst conditions (to spend all the response time in each round).

As an incentive when the game ends, it is displayed one congratulatory message such as "Congratulations for your result" or "Great, but a next time try to do better".

The player is encouraged to play again in order to try to get a better score if he/she cannot complete the game. If the player is running the game in online mode, all the results obtained by level and by round, such as response times, numbers of correct or incorrect responses and final result will be sent to the remote server. 


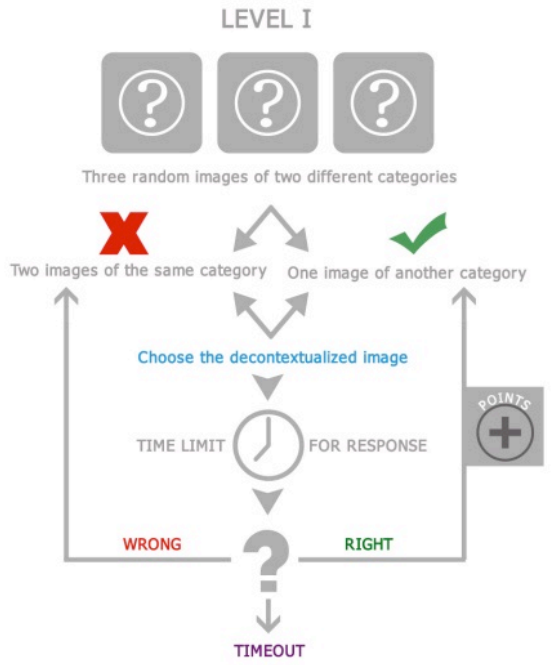

\section{Web Portal}

To support the game Total Challenge, a Web Portal was developed. The game is not built into the Web Portal; it is a standalone application that communicates with a database shared with the game Portal. The Web Portal plays no direct role in running the game. It has two main functions, one being addressed to users and other to researchers. Concerning the first, the Web Portal serves to make an interface between the user and the game and for its dissemination and support. As regards the researchers, it serves as a platform for managing and monitoring crucial results for research to be undertaken.

We chose sober, simple and generalist design and interaction for the Portal interface, so that the browsing experience in the Web Portal, by the user, was fluid, without difficulties in achieving a particular purpose.

Navigation throughout the Portal is quite simple and intuitive based on two menus: general and the user menu (Fig. 13). The first menu, always visible to the user horizontally at the top of the Web Portal provides access to the several general sections, such as the game description and contacts, among others. The second only becomes visible (also in a horizontal position below the previous one) when the user is authenticated, giving him access to the individual functionalities of each institution, such as to add a player, view players, among others.

On the first page of the Web Portal we can see that it makes a generalist approach to the game "Total Challenge". On this page are also highlighted the main portal potentialities and the updated news. The user's login section is also present on this page, being one of the most important areas of the Web Portal.

In the section "Total Challenge" the user can see in detail the description, scope, characteristics, the target audience, game screenshots and other relevant information, even before to log. He/she can also access other sections: "Downloads", "Press", "Contacts" and "Register."

The latest versions of "Total Challenge" for the various platforms (Windows, Macintosh and Linux) are available
LEVEL II

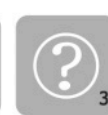

es of any category

THE IMAGE ORDER
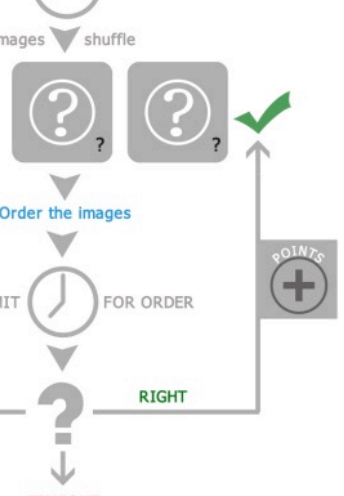

TIMEOUT
LEVEL III

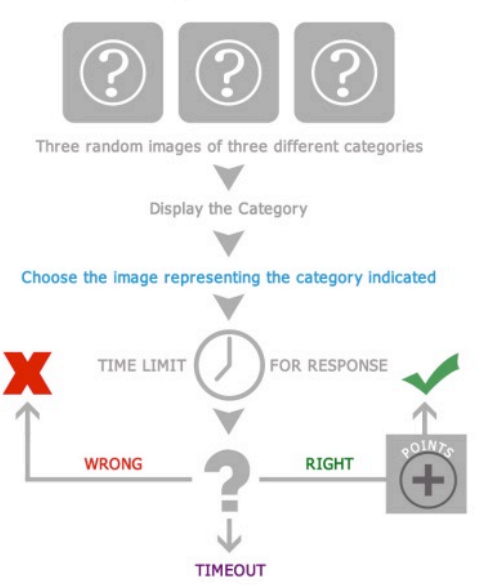

for download in the "Downloads" section. The game instructions for use are also available.

In the "Press" section we can see the most relevant media news, as well as publications in newspapers, magazines and scientific papers.

The "Contacts" section contains a contact form for users to submit their questions and suggestions for the research team.

The "Register" section is currently only available to institutions through the responsible person. In this section it will be required information (name of institution, address, city, postcode, telephone and email, name of the responsible person, their position in the institution and email). The responsible must choose a username and password. When the registration is made, an email to the responsible will be sent in order to he/she confirm it. After this procedure, the institution does not have yet privileges to $\log$ into the platform. The sent information must be processed, analyzed and approved by the research team. Achieved this approval it will be sent an email to inform that the account has been activated. From this moment, the institution can authenticate to the platform, to access personal area.

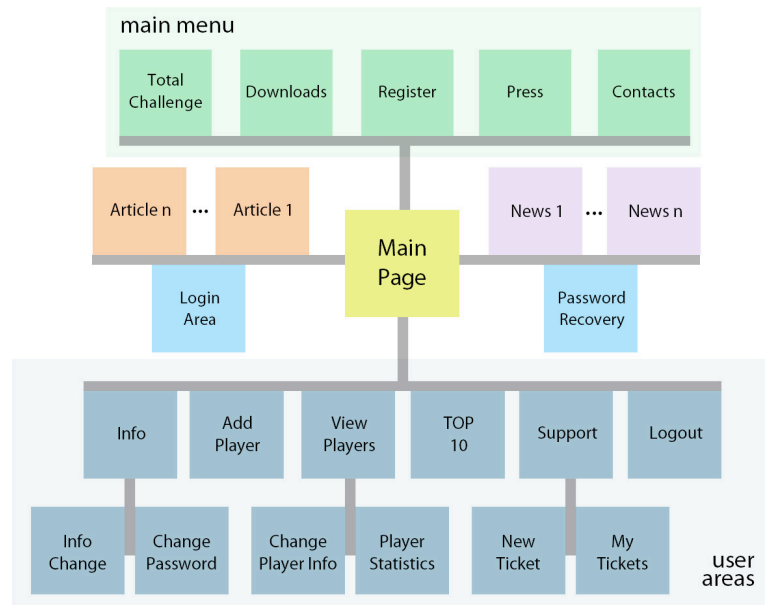

Figure 13. Navigation structure of the web portal 
In case the user forgets the password, the Web Portal can perform its recovery. Once all the passwords stored in the database are encrypted, there is theoretically no possibility of recovering. Thus, when a user forgets his/her password, he/she can generate another one, as described next. At first, the system requests the username or email. If the username or email address exists in the database, it is sent to the personal email a link to renew the password (this step is to ensure that it is the user who requested the password recovery). By entering the link sent to the email, there is a regeneration of the user password, which will also be sent to his/her email. After this process, the user can do, again, the login in the Web Portal with his/her username and new password generated. If the user wants to change this password, he/she can do it in the personal area, when he/she is authenticated.

After logging into the Web Portal, the user will observe a new user menu with the sections described below: the Institution's Information (Info), Add Players, View Players, Top 10, Support and Logout.

In the "Info" section, the user gets the information he entered when the institution was registered in the Web Portal. It is also available an option to password change, very useful when using the password recovery application.

In the "Add Player" section, the user can add players to the game. Information is requested as the player's name, age, gender, type of disability (some are listed), education, and related problems (e.g., motor, hearing or other).

In the "View Players" section (Fig. 14), the user can see the username and the login password in the game of each player and he/she can also change the information of any player eliminate him/her or see the statistics and the charts of his /her evolution. In these statistics, the user can access the average response time at each level of game or of difficulty, among others.

In the "Top 10" section, the user will find the ranking of the top 10 players in the various types of disabilities, at a certain level of difficulty. The user can also see the best players, whether at all institutions or within his/her own institution.

In the "Support" section, the user can take a support ticket with a certain priority level (Normal or Urgent). Upon receipt of the request for support, the team will respond to this request under the rules of screening: date of the support request and priority level. The user can see at any time, their support requests, read the exchanged messages, and observe the process status (open or closed).

Finally, the "Button Logout", allows the user logout of the portal, an essential task when he/she is using a public computer in order to prevent another user to improperly use the platform (Fig. 15).

\section{FINAL REMARKS}

The changes that teaching has been experimenting over the years have been clearly visible, being also notable the efforts to make learning more enjoyable and more motivating. The solution seems to lie in the use of serious games that, in a dynamic way, combine educational contents with fun activities.

In formal education, children are subordinated to rules imposed by adults, feeling obliged to give up what they want. And it seems to be here the paradox of the serious game: although it is characterized by a set of rules, children tend to regard it as an activity that stimulates compe-

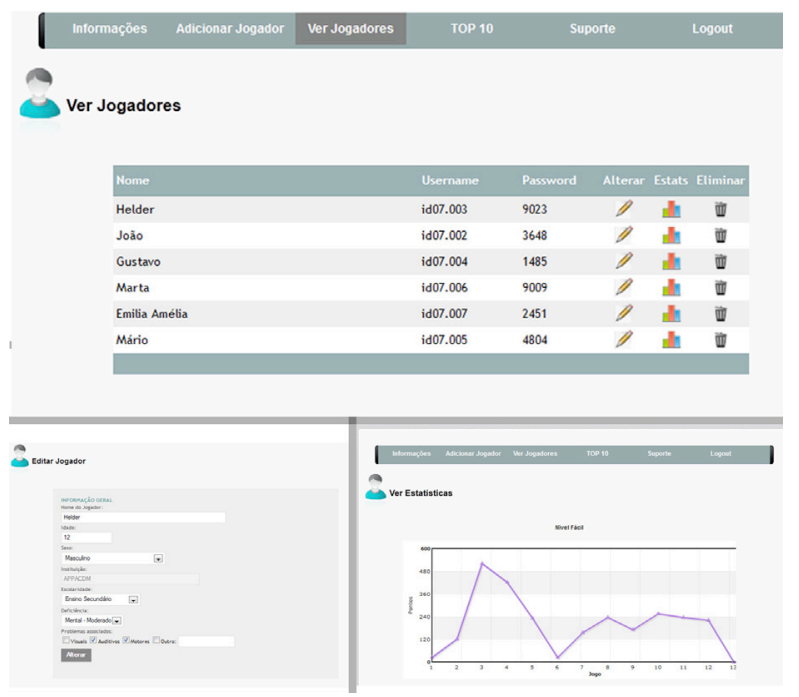

Figure 14. View Players section

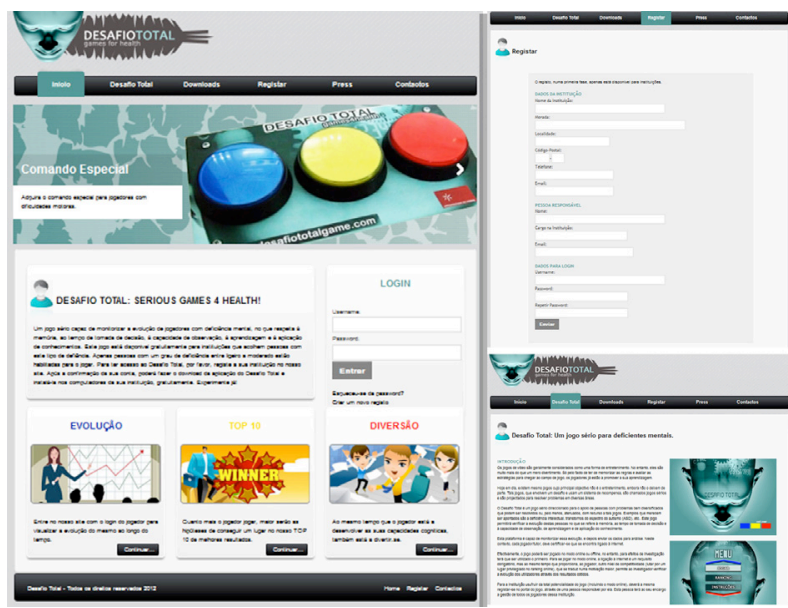

Figure 15. Graphical interface of the web portal

tition, giving them the feel of a space detached of norms and impositions, that make them to be in tune with the adults, trying, only, to achieve their goals. Thus the conditions for a more effective learning are created, which allows maximizing the construction of knowledge.

Since people who have been diagnosed with intellectual disability or autism spectrum disorders have limitations at different levels, it is necessary to provide them with personalized and appropriate support, in order to improve their social life.

Research has shown that serious games are a good way to provide such support, since, by using them, the person feels free to express and explore his/her feelings, thoughts, experiences, fears and behaviors.

Having features like competition, goals, rules, challenges, choices, and fantasy, serious games can trigger the necessary motivation to facilitate learning and also check the progress of people with intellectual disability or autism spectrum disorders, in relation to memory, the time of decision making and observation, learning and applying knowledge skills.

It is the author's belief that the Total Challenge may be a successful tool in relation to the development of cognitive skills of children and the progress of people with the reported impairments. However, there are still no statistical results, which we propose to present in future work. 


\section{REFERENCES}

[1] C. Duflo, "O jogo: de Pascal a Schiller". Porto Alegre, Artmed, 1999.

[2] J. Huizinga, "Homo ludens: A study of the play-element in culture". Boston: Beacon Press, 1970.

[3] E. M. S. M. Araújo, "O desenho de videojogos na motivação de pacientes com necessidades de reabilitação fisioterapêutica". Dissertação de Mestrado em Ilustração e Animação. Barcelos, Portugal: Instituto Politécnico do Cávado e do Ave, 2015.

[4] T. Martins, V. Carvalho, and F. Soares, "An Overview on the Use of Serious Games In Physical Therapy and Rehabilitation”. In: M. M. C. Cunha, (ed.), Handbook of Research on Serious Games as Educational, Business and Research Tools, IGI-Global, Hershey, 2012, pp.1175-1187. http://dx.doi.org/10.4018/978-1-4666-01499.ch061

[5] T. Martins, V. Carvalho, and F. Soares, "Application for physiotherapy and tracking of patients with neurological diseases - preliminary studies," SeGAH 2013, IEEE 2st International Conference on Serious Games and Applications for Health, Algarve, Portugal, May, 2013, pp. 1-8.

[6] T. Martins, V. Carvalho and F.Soares, "Monitoring of Patients with Neurological Diseases: Development of a Motion Tracking Application Using Image Processing Techniques," International Journal of Biomedical and Clinical Engineering (IJBCE), JulyDecember 2013, Vol. 2, N. 2, pp.37-55. http://dx.doi.org/10.4018/ ijbce. 2013070104

[7] T. Martins, M.Araújo, O. Lopes, V. Carvalho, F. Soares, D. Matos, J. Marques, J. Machado, and L. Torrão, "PhysioVinci - Solução Integrada para Reabilitação Física de Pacientes com Patologias Neurológicas," ACM, 2014.

[8] T. Martins, M. Araújo, V. Carvalho, F. Soares, and L. Torrão, "PhysioVinci - A first approach on a physical rehabilitation game," The Fifth International Conference on Serious Games Development \& Applications, Berlin, Germany, 9-10 October, 2014. http://dx.doi.org/10.1007/978-3-319-11623-5 1

[9] H. M. Vilas, "Jogos de computador para a formação em engenharia informática”. Dissertação de Mestrado em Informática. Guimarães, Portugal: Universidade do Minho, 2012.

[10] P. J. Standen, and D. J. Brown, "Virtual reality and its role in removing the barriers that turn cognitive impairments into intellectual disability," Virtual Reality vol. 10, May 2006, pp. 241-252, http://dx.doi.org/10.1007/s10055-006-0042-6

[11] J. Kay, J. A. Lieberman, and A. Tasman, Psychiatry: Behavioral Science Clinical Essentials. Philadelphia: W. B. Saunders Company, 2000.

[12] A. J. G. Vieira, "Concepção, planeamento, realização e avaliação de um programa de natação adaptada numa população com deficiência intelectual com e sem síndrome de Down. Dissertação para obtenção do grau de mestre em actividade física adaptada, pela Faculdade de Desporto da Universidade do Porto, Porto, 2009.

[13] C. S. Lanyi, and D. J. Brown, "Design of Serious Games for Students with Intellectual Disability," Proc. Human Computer Interaction 2010/Interaction Design for International Development 2010 Conference, HCI 2010/IDID 2010, March 2010, pp. 1-11.

[14] M. T. E Mantoan, "A construção da inteligência nos deficientes mentais: um desafio, uma proposta, Cadernos de Educação Especial, Santa Maria, vol. 1, no. 1, pp. 107-114, 1992.

[15] A. Medalia, and N. Revheim, Dealing with Cognitive Dysfunction Associated with Psychiatric Disabilities. New York, Office of Mental Health Family Liaison Bureau, 2002.

[16] R. M. S. L. Hollerbusch, "O desenvolvimento da interacção social das crianças com alteração do espectro do autismo". Dissertação de mestrado, Faculdade de Ciências do Desporto e de Educação Física - Universidade do Porto, Porto, (2001).

[17] R. L. Schalock, R. A. Luckasson, and K. A. Shogren, "The Renaming of Mental Retardation : Understanding the Change to the Term Intellectual Disability," Intellectual and Developmental Dis- abilities Vol. 45, No. 2, April 2007, pp. 116-124, http://dx.doi.org/10.1352/1934-9556(2007)45[98:AOMTTC]2.0. $\mathrm{CO} ; 2$

[18] D. Michael, and S. Chen, "Serious games: Games that educate, train, and inform". Boston, MA.: Thomson Course Technology, 2006.

[19] N. F. V. Ponte, "Um jogo sério sobre realidade económica/financeira de Portugal". Dissertação de Mestrado em Engenharia Informática e de Computadores. Lisboa, Portugal: Instituto Superior Técnico, 2013.

[20] M. Antičević, "Creación de juegos serios en Unity 3D”. Trabajo Fin de Máster en Investigación en Informática. Madrid, España: Universidad Complutense de Madrid (UCM), 2014.

[21] S. D. Emmerich, "Archetypes, Learning, and Games". Master thesis in Game Production. Orange County, FL: Full Sail University, 2010.

[22] Minnesota Educational Computing Consortium, "Number Munchers". Minnesota: the author, 1986.

[23] A. J. Stapleton, "Serious games: Serious opportunities". Paper presented at the Australian Game Developers' Conference, Academic Summit, Melbourne, VIC, 2004.

[24] C. P. Santos, and V. R. Bourscheidt, "Concepção de Jogos Educacionais Sensíveis ao Conteúdo”. Nuevas Ideas en Informática Educativa TISE 2013, pp. 826-829.

[25] J. P. Kincaid, and K. Westerlund, "Simulation in education and training," Proceedings of the 2009 Winter Simulation Conference, 2009, pp. 273-280. http://dx.doi.org/10.1109/WSC.2009.5429337

[26] D. Charsky, "From Edutainment to Serious Games: A Change in the Use of Game Characteristics". Games and Culture Vol. 2, N. 2, 2010, pp. 177-198. http://dx.doi.org/10.1177/15554120093 54727

[27] P. D. Scaico, D. Lopes, M. A. Azevedo, J. C. Silva, S. V. Mendes Neto, E. 1. F. Falcão, "Implementação de um jogo sério para o ensino de programação para alunos do ensino médio baseado em $\mathrm{m}$ learning”, Anais do XX Workshop sobre Educação em Computação, Curitiba, Brasil, 2012.

[28] Urturi, Z.S, Zorrilla, A.M., \& Zapirain, B.G. (2011). Serious Game based on first aid education for individuals with Autism Spectrum Disorder (ASD) using android mobile devices. In Q. Mehdi, A. Elmaghraby, R. Moreton, R. Yampolskiy, \& J. Chariker. http://dx.doi.org/10.1109/cgames.2011.6000343

[29] van Veen, M., de Vries, A., \& Cnossen, F. (2009). Improving collaboration skills for children with PDD-NOS through a multitouch based serious game. Groningen NL: University of Groningen.

\section{AUTHORS}

Vítor H. Carvalho is with University of Minho, IPCAEST \& Algoritmi Research Centre, Portugal (vcarvalho@ipca.pt).

Tiago Martins is with University of Minho, Algoritmi Research Centre, Portugal (tiagorsmartins@hotmail.com).

Filomena Soares is with University of Minho, Algoritmi Research Centre, Portugal (fsoares@dei.uminho.pt).

Miguel Araújo is with University of Minho, IPCAEST, Portugal (miguelmaraujo@gmail.com).

This work has been supported by FCT - Fundação para a Ciência e Tecnologia in the scope of the project: UID/CEC/00319/2013. The authors are also grateful to the Portuguese Foundation (FCT) for funding through the SFRH/BD/74852/2010 PhD scholarship." This article is an extended and modified version of a paper presented at the the International Conference on E-learning in the Workplace 2015 (ICELW'15), held in June 2015, at Columbia University in New York, NY, USA. Submitted 28 July 2015. Published as resubmitted by the authors 23 September 2015. 